\title{
Identifying content knowledge for teaching energy: Examples from high school physics
}

\author{
Amy D. Robertson, Rachel E. Scherr, Lisa M. Goodhew, \\ Abigail R. Daane, Kara E. Gray, and Leanna B. Aker \\ Department of Physics, Seattle Pacific University, Seattle, Washington 98119-1997, USA
}

(Received 5 April 2016; published 25 January 2017)

\begin{abstract}
"Content knowledge for teaching" is the specialized content knowledge that teachers use in practicethe content knowledge that serves them for tasks of teaching such as revoicing students' ideas, choosing an instructional activity to address a student misunderstanding, and evaluating student statements. We describe a methodology for selecting and analyzing classroom episodes showing content knowledge for teaching about energy (CKT-E), and illustrate this methodology with examples from high school physics instruction. Our work has implications for research on teacher knowledge and for professional development that enhances teacher CKT-E.
\end{abstract}

DOI: 10.1103/PhysRevPhysEducRes.13.010105

\section{INTRODUCTION}

For decades, we as an education research community have asked ourselves what teachers need to know to teach well. One answer to this question is that teachers need a specialized form of knowledge, often called pedagogical content knowledge (PCK, [1,2]) or content knowledge for teaching (CKT, $[3,4])$. Shulman introduced the idea of PCK in the 1980s, defining it as "that special amalgam of content and pedagogy that is uniquely the province of teachers, their own special form of professional understanding" [2]. As we will discuss in Sec. II, scholars since Shulman have debated what should be included in conceptualizations of teacher knowledge (including PCK) and how PCK should be developed or measured. One major strand of this scholarship examines what teachers need to know to teach particular topics within a domain, such as fractions in mathematics [4] or genetics in science [5]. Our NSF-funded project, "Assessing, validating, and developing content knowledge for teaching energy," has followed in this tradition, seeking to answer the question, "What do high school teachers need to know to teach energy in the context of mechanics?"

There are many facets of what teachers need to know to teach energy, in part because the job of teaching is multifaceted: teachers engage in a multitude of tasks of teaching [3,4], from planning lessons, to assessing student work, to answering student questions during the flow of an activity. One important task of teaching-central to the vision of recent reforms in science and mathematics education $[6,7]$ - is attending to and interacting with the substance of students' scientific and mathematical ideas

Published by the American Physical Society under the terms of the Creative Commons Attribution 3.0 License. Further distribution of this work must maintain attribution to the author(s) and the published article's title, journal citation, and DOI.
[8-15]. Though there is a rich history of research that describes common student ideas in different STEM domains [16-18], the nature and substance of student ideas as they emerge in the flow of classroom activity is always somewhat unexpected, such that teachers must draw on their knowledge in the moment in improvisational ways $[8,19]$. Our subteam-comprised of the authors of this manuscript-has focused on the facets of teacher knowledge that are involved in this interactional task of teaching, or tasks of teaching that center on responding to students' ideas about energy. Instead of asking, "What do high school teachers need to know to teach energy in the context of mechanics?," writ large, we want to know more about what knowledge teachers use as they interact with and respond to student thinking about energy in the flow of classroom discourse.

In seeking to answer the question of what knowledge teachers are using as they interact with student thinking in the classroom, we developed a methodology for selecting and analyzing classroom episodes showing teacher contentknowledge-for-teaching-energy-in-use (CKT-E-in-use). This paper presents this methodology and draws on examples from high school physics to illustrate its use. We situate this work in the broader agenda of research on teacher knowledge. In particular, Alonzo and Kim [20] argue that the notion of pedagogical content knowledge has strong intuitive appeal but that "empirical evidence demonstrating a connection between PCK and teaching practice or student learning outcomes has been mixed." They suggest two possible responses to the "lack of convincing evidence of PCK": (i) reject the construct as a meaningful way of describing teacher expertise, or (ii) question how PCK has been measured. In taking up (ii), they further suggest that "declarative PCK"or "knowing that," for example, energy is conserved or that students often conflate forces with energy - "may not have as much effect on what happens in moment-to-moment classroom interactions" as "dynamic PCK"- or PCK that shows 
up in teachers' "activities during a lesson." Our work has the potential to contribute to the measurement of what Alonzo and Kim call dynamic PCK, and so ultimately to support researchers in answering broader questions about what matters in teacher interactions with students about energy.

While not our primary contribution, our analysis of teachers' CKT-E-in-use also contributes to the larger conversation about physics teacher preparation and professional development that is grounded in conceptualizations of CKT. As we will discuss in the following section, there is no clear consensus about what PCK or CKT is. This lack of coherence can contribute to the feeling that CKT "includes almost everything a teacher might know in teaching a particular topic" [4], rather than demarcating a specialized set of knowledge that is unique to the domain of teaching. This can present substantial challenges to physics teacher educators as they make decisions about what to focus on in content courses for pre- and in-service teachers. Our analysis highlights important considerations about knowledge use - not only knowledge possession-that we will discuss in more detail in Sec. VI, after we look carefully at examples from teacher practice.

We start (Sec. II) by reviewing the concept of "content knowledge for teaching" in the education research literature. In Sec. III, we discuss our data collection techniques, and in Sec. IV, we articulate our methodology for identifying CKT-E. Section V gives examples of how we used our methodology to identify teacher CKT-E, organized by the tasks of teaching this CKT-E serves. Section VI recaps our argument and delineates limitations and implications of our work.

\section{THE CONCEPT OF "CONTENT KNOWLEDGE FOR TEACHING"}

In the STEM education research literature, there is substantial disagreement about the constructs of PCK and CKT. Major science education research journals (e.g., International Journal of Science Education, Science Education) have published thousands of articles describing the development and manifestation of teachers' pedagogical content knowledge in science. One consequence of this proliferation is that there is no clear consensus about what pedagogical content knowledge is. For example, even among scholars whose work in pedagogical content knowledge is considered seminal [1-4,21,22], there is disagreement about the forms of knowledge needed for teaching and the relationships between these forms. Ball, Thames, and Phelps [4] write,

"Throughout the past 20 years, for example, researchers have used pedagogical content knowledge to refer to a wide range of aspects of subject matter knowledge and the teaching of subject matter and, indeed, have used it differently across-and even within-subject areas. Besides differences in the breadth of what the term includes, there have been significant differences in how the term is used to relate content knowledge to the practice of teaching... Particularly striking is the lack of definition of key terms. Pedagogical content knowledge is often not clearly distinguished from other forms of teacher knowledge, sometimes referring to something that is simply content knowledge and sometimes to something that is largely pedagogical skill. Most definitions are perfunctory and often broadly conceived... When defined in these ways, pedagogical content knowledge begins to look as though it includes almost everything a teacher might know in teaching a particular topic, obscuring distinctions between teacher actions, reasoning, beliefs, and knowledge."

Abell [23] echoes this, saying, "the science education PCK literature lacks coherence and is difficult to characterize," as do van Driel, Berry, and Meirink [24], who write, "research has not found shared features of teacher knowledge, for all teachers, at a large scale."

In spite of this lack of consensus, most scholars trace the origin of the construct of PCK back to Shulman, who defined PCK as "that special amalgam of content and pedagogy that is uniquely the province of teachers, their own special form of professional understanding" [2]. In science and mathematics education, researchers often build on the characterization of CKT developed by Ball and colleagues in the 1990s and early 2000s. Ball's interest in understanding the content knowledge unique to teaching mathematics led her and her colleagues to look closely at the "tasks involved in teaching [mathematics] and the mathematical demands of those tasks" [4]. She found that many of these tasks drew on "mathematical knowledge apart from knowledge of students or teaching." She argued that in many cases the mathematical knowledge that teachers were using was specialized to the profession of teaching; it was "mathematical knowledge not typically needed for purposes other than teaching" [4]. In other words, Ball proposed that teachers' (unique) professional knowledge included not only PCK but also specialized content knowledge (SCK). She coined the term "content knowledge for teaching" (CKT) to represent teachers' specialized professional knowledge, with SCK and PCK as subdomains of this knowledge.

In this paper, we build on Ball's characterization of CKT, focusing on the CKT that teachers draw on in interactional tasks of teaching, which we define as tasks of teaching that center on responding to students' ideas (in this case about energy). Ball's characterization [4] parses CKT according to the scheme in Fig. 1: CKT includes subject matter knowledge and pedagogical content knowledge, which each have their own subdomains. The subdomains in Ball's characterization of teacher knowledge overlap with other seminal characterizations, which often include curricular knowledge (or knowledge of students and curriculum) [4,21,25,26], 


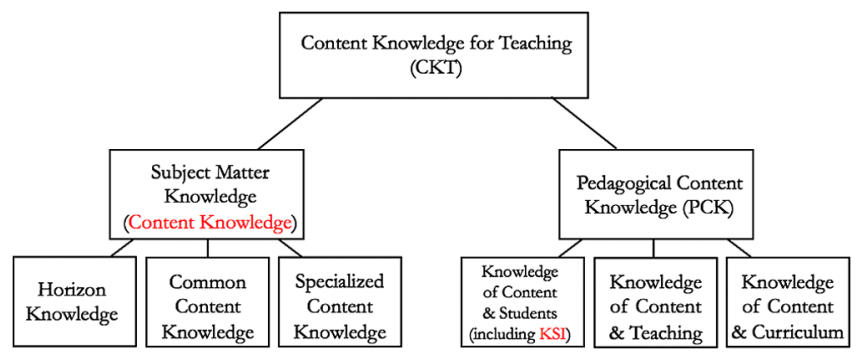

FIG. 1. Relationships between CKT, content knowledge, PCK, and KSI, based on Ball, Thames, and Phelps.

knowledge of instructional strategies (included in knowledge of content and teaching) $[1,4,21,25,26]$, knowledge of students' understandings (included in knowledge of content and students) $[1,4,21,25,26]$, and content knowledge. ${ }^{1} \mathrm{We}$ limit our analysis to teacher content knowledge and knowledge of student ideas (both red in Fig. 1), since we expect these to be most visible in interactional tasks of teaching. We consider CKT-E to be CKT in the context of energy, such that all of the entities in Fig. 1 would be followed by an "-E."

We also draw on Ball's framework for identifying CKT. Like Ball, we assume that the tasks of teaching energy draw on specialized knowledge, and that we can locate and identify such knowledge by looking closely at teaching practice. The term "task of teaching" was invented by Ball and her colleagues to describe the "fundamental activities [that] are demanded by the broad aims of developing a classroom in which mathematics is treated with integrity, students' ideas are taken seriously, and mathematical work is a collective as well as an individual endeavor" [4]. When inferring content knowledge for teaching mathematics, these researchers first identified tasks of teaching on the basis of their collective experience as teachers and researchers. From there, they asked the question of what mathematical knowledge is entailed by these tasks. For example, Ball and Bass [3] highlight the knowledge entailed by the task of evaluating the viability of alternative multiplication strategies. They show that in evaluating the three solutions for multiplying $35 \times 25$ in Fig. 2, a teacher "must be able to ask what is going on in each of these approaches and to know which of these is a method that works for multiplying any two numbers." Doing so requires not only that teachers be "able to multiply $35 \times 25$ themselves." It also requires understanding the distributive property: to sort out what is going on in solution $\mathrm{C}$, the teacher must know "that $35 \times 25=(30 \times 20)+(5 \times 20)+(30 \times 5)+(5 \times 5)$." $\quad$ And further mathematical knowledge is called on in determining whether the solution strategies instantiated in A, B, and C

\footnotetext{
${ }^{1}$ Ball also includes horizon knowledge, which she and her colleagues define as an "awareness of how mathematical topics are related over the span of mathematics included in the curriculum."
}

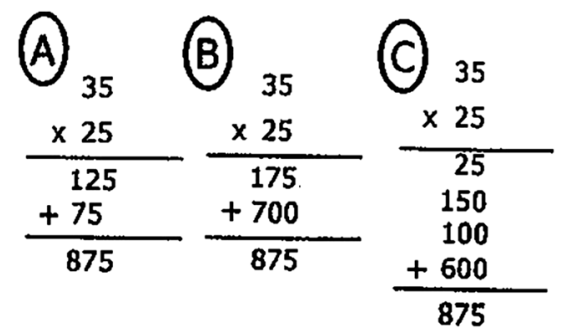

FIG. 2. Example from Ball and Bass [3].

are generalizable (i.e., would work for other multiplication problems).

\section{DATA COLLECTION}

Our analysis was a part of a larger study that aimed to document and support the development of teachers' CKT-E. In the study's first year, twelve teachers (six in the Pacific Northwest and six in the metropolitan Northeast) were recruited using high school teacher email listservs as well as by word of mouth. For this analysis, we selected video episodes that met a set of criteria described in Sec. IV C. These episodes were associated with three of the twelve teachers, all of whom taught physics in public high schools in the Pacific Northwest. All three teachers were white, as were the majority of the students in their schools.

Video data collection was informed by the project's prioritization of teacher-student interactions. Specialized cameras recorded video from two different vantage points in a classroom: depending on the classroom, cameras may have been aimed at student groups (to capture the teacher's interactions with those groups), the front of the class (to capture the teacher's interactions with the class as a whole), or some other focal point appropriate to that classroom. Audio was recorded through a lapel microphone worn by the teacher. The video output is a split screen combining images from the two cameras (see Fig. 3 for an example). After initial setup by a researcher, the teacher only needed to turn the unit on and off daily and wear the lapel microphone. Video data were automatically transferred to a remote server whenever the cameras were not recording. No researcher was present in the classroom during instruction. Benefits of the video data collection system include ease of use for the teacher and minimization of time

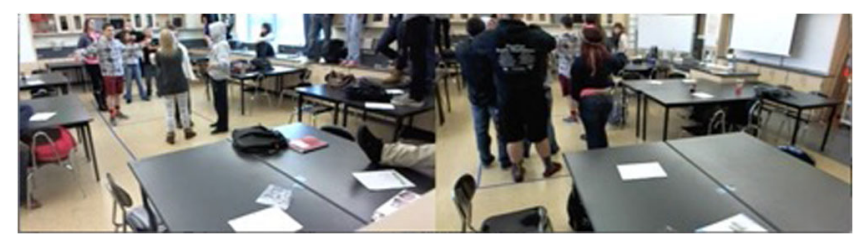

FIG. 3. Snapshot illustrating split-screen video capture. For perspective, the right camera is placed behind students in the background of the left image. 
that the researchers spent in the field. Limitations of the system include lack of researcher field notes and lack of researcher monitoring of the recording system, sometimes resulting in poor audio or unfavorable camera angles. While the automatic data transfer was a major convenience, it was not always timely, which sometimes precluded realtime correction of a technical problem. This system of cameras, microphones, data processing, and secure online storage was a commercial package designed to support teachers in reflecting on their teaching practices.

In addition to video data, this research project collected what was intended to be comprehensive documentation of the participating teachers' energy instruction. Each participating teacher was interviewed before their energy instruction took place to learn their plans and goals for the energy unit. Participating teachers and their students both took a project-designed assessment intended to measure students' science achievement before energy instruction. For each participating teacher, one class period was videotaped every day of energy instruction. The project collected all energyrelated instructional materials including lesson plans, lecture notes, worksheets, quizzes, homework, and exams. The project also collected samples of student work for the class period recorded, along with the teacher's evaluation of the quality of that work and explanation of his or her evaluation criteria. Teachers submitted a daily reflection on their energy instruction. After the energy unit, each participating teacher was interviewed to learn their perspective on how the energy instruction had gone, including the extent to which they had met their instructional goals. They and their students completed a written assessment of their conceptual understanding of energy. Finally, the participating teachers each completed a multiple-choice assessment of their content knowledge for teaching energy [27].

\section{METHODOLOGY FOR IDENTIFYING TEACHERS' CKT-E}

Fundamental to the methodology described in this section is the assumption that teachers draw on CKT-E in tasks of teaching. We are specifically interested in interactional tasks of teaching, which we define as those tasks of teaching that center on responding to students' ideas about energy. Given the theory of CKT that we presented in Sec. II, this suggests that interactional tasks of teaching, by definition, draw on knowledge of students' ideas (KSI). KSI may include knowledge the teacher has already (e.g., based on literature about student ideas in particular domains) or knowledge the teacher constructs in-the-moment (e.g., based on inferences from student statements).

As we will show in this section, our episode selection criteria are meant to point us to instances in which teachers are engaged in interactional tasks of teaching, and our identification of the tasks of teaching instantiated by a given episode is guided by our sense of how a teacher is interacting with student ideas (i.e., which of their actions are drawing on
KSI). We also describe - and then illustrate-how we infer content knowledge and knowledge of students' ideas within episodes of teaching.

\section{A. Episode selection}

We selected episodes for analysis in which the teacher and students were interacting around students' energy ideas (i.e., episodes in which teachers were engaged in interactional tasks of teaching). The first stage of selection was for one researcher (Goodhew) to select and transcribe long sessions of classroom video (typically 15-20 min) in which both teachers and students were talking. The second stage of selection was for the same researcher to identify when teachers and students were talking about energy. These two stages were informed by the assumption that rich instances of interactional tasks of teaching in the context of energy would include substantive dialogue between teacher and students. The third stage of episode selection was for the research team (all authors) to collaboratively view these long sessions and segment them into episodes, indicated by shifts in activity such as changes in personnel, movement of participants in space, or the introduction and manipulation of new objects [28]. The fourth stage of episode selection was also the first stage of analysis: For each episode that we selected, we identified the task of teaching, the energy content knowledge, and the knowledge of student ideas that were indicated in the episode (see Secs. IV B and IV C). This process produced approximately 50 episodes' worth of preliminary analysis.

To select episodes for presentation here, we applied a fifth filter: evidence that student statements influenced teacher statements, i.e., the teacher responded in some way to student ideas about energy. From the list of episodes that remained after applying this fifth criterion, we selected the ones for which there were especially high levels of interaction between teacher and students, or especially high visibility of students' science ideas. Our selection was further guided by our desire to illustrate several tasks of teaching as enacted by a few different teachers.

\section{B. Identification of tasks of teaching}

Our analysis seeks to illustrate how to identify the knowledge that teachers are drawing on during interactional tasks of teaching, with particular attention to teachers' content knowledge and knowledge of students' ideas. In identifying and naming interactional tasks of teaching, we took a slightly different approach than Ball and her colleagues, who used their collective experience as teachers and researchers to articulate central tasks of teaching mathematics. We first identified episodes in which (i) there were high levels of student-teacher discourse about energy and in which (ii) student statements influenced teacher statements, assuming that such episodes would instantiate interactional tasks of teaching. To articulate the specific tasks of teaching instantiated in our episodes, we attempted 
to characterize how the teacher was responding to students' ideas: was the teacher evaluating the idea(s), revoicing it or them, interpreting it or them, etc.? For example, if a student answered a teacher's question and the teacher provided positive or negative feedback about the students' answer, we said that the teacher was evaluating the student's idea.

After we had selected several episodes, we grouped them according to the action the teacher took in response to the student idea, and finalized the names we gave to the interactional tasks of teaching based on similarities between episodes. For example, we originally had separate categories for "affirming a student's correct answer" and "evaluating a student's contribution." Both of these teacher responses represent an evaluative action, so they were combined into a single task of teaching: evaluating student ideas.

Our organization of our analysis around tasks of teaching (in Sec. V) reflects the assumption that such tasks of teaching draw on or entail CKT-E (including KSI and content knowledge). ${ }^{2}$ This means that one way of answering the question "What do teachers need to know to teach topic $x$ ?" begins with identifying the "fundamental activities" [4] that teachers engage in as they respond to student ideas in the moment, and then proceeds to inferring the knowledge used by teachers as they do so.

\section{Inference of content knowledge for teaching energy}

Our interest in identifying the CKT-E that teachers use as they engage in interactional tasks of teaching about energy led us to focus on the content knowledge and knowledge of student ideas dimensions of CKT. To be clear, by "knowledge" we mean teachers' knowledge in use; we do not mean to imply that teachers have this knowledge in a stable sense [29]. (Though the latter may be true, we do not have sufficient evidence to make such claims.)

We identify teacher content knowledge in teachers' selections from and additions to student statements; these selections and additions provide evidence of the teacher's knowledge as distinct from the student's. For example, the following is an excerpt from an interaction in an eighthgrade physical science class. Mr. Diaz, ${ }^{3}$ the teacher, has been talking with a group of five students, as they share their sense of whether various everyday scenarios (e.g., a bus driving down the street, leaves blowing in the street, a ball rolling across a flat surface) "involve energy." The group extensively debates whether the leaves in the street have energy, or whether they just use energy from the wind. One central consideration for them is that the leaves can burn, and so seem to have energy, but that they need a

\footnotetext{
${ }^{2}$ For example, our characterization of interactional tasks of teaching in terms of how the student acted on student ideas assumes that such actions draw on KSI. This assumption suggests that we can infer teachers' KSI by looking carefully at what knowledge such actions require.

${ }^{3}$ All teacher and student names are pseudonyms.
}

source to move. Near the end of the discussion, Danielle and Christopher, both students, engage in the following dialogue with Mr. Diaz:

1. Christopher: If there's like a dead person, I don't think it would have energy, but you could roll it down a hill.

2. Danielle: You could burn it.

3. Christopher: And I don't think the person had any energy.

4. Mr. Diaz: Hold on, hold on. It sounds like one of the issues that's coming out is that we might need to start dealing with different types of energy. There might be different things going on with different types, and that could be an issue.

In this excerpt, we see evidence of Mr. Diaz's content knowledge that energy has different forms associated with different observable quantities in the addition he makes to these students' reasoning in line 4: Danielle suggests energy associated with burning, and Mr. Diaz adds the idea of energy types. We also see evidence of teacher content knowledge in instances where the teacher prioritizes a certain part of what students say, asks questions that highlight a particular feature of students' ideas, or asks questions that direct student attention to something they had not been discussing.

We identify teacher knowledge of student ideas in teacher responses that are plausibly informed by an understanding of their students' actions or statements, or by an understanding of literature about student ideas about energy. In the example above, Mr. Diaz's sense that they might need to consider different types of energy is plausibly grounded in the conversation that his students have been having: they are struggling to decide whether the leaves (or the dead person) have energy because, on the one hand, leaves can burn, but on the other hand, they cannot move without the wind. We infer that Mr. Diaz thinks that understanding that an object can have different kinds of energy - e.g., chemical and motion energy - may help them to resolve their own question. We also see evidence of teacher knowledge of student ideas in, for example, instances where an instructional activity seems designed to address common (documented) misunderstandings about energy, or where the teacher revoices a particular student idea.

All of the interactional tasks of teaching we identified, by definition, are informed by teachers' knowledge of student ideas. In the following examples, we both state generally (and early on) how the task of teaching itself plausibly draws on KSI, as well as the specific KSI that we infer in each episode.

\section{ILLUSTRATING THE METHODOLOGY: EXAMPLES OF CONTENT KNOWLEDGE FOR TEACHING ENERGY}

Our purpose in this section is to illustrate teachers' content knowledge for teaching energy - in particular, to show teachers using content knowledge and knowledge 
of student ideas in the context of interactional tasks of teaching. The tasks of teaching for which we share examples include (a) inferring students' model of energy from their expressed ideas, (b) revoicing students' ideas, (c) choosing an instructional activity to address a student misunderstanding, and (d) evaluating student ideas.

\section{A. Inferring students' model of energy from their expressed ideas}

One interactional task of teaching energy is to use the energy ideas that students express to infer their model for energy. For example, if a student says "the leaves in the street are pushed by energy," a teacher may infer that the student is referring to energy as though it is a force [30]. This task of teaching requires teacher knowledge of student ideas in a particularly straightforward way: teachers engaging in this task are interpreting student statements in real time to learn what students know, and then using that information to make pedagogical decisions. In the examples that follow, teachers use student statements to infer students' models of energy, and make instructional moves on the basis of those inferences.

\section{Ms. Allen infers students' model of energy supply}

In the following episode, a secondary teacher, Ms. Allen, discusses with her class the energy transfers and transformations that occur when a person pushes a box with her hand. Her students are using a representation called Energy Theater [31-33], in which units of energy are represented by people, and objects in the scenario (such as the box, or the hand of the person doing the pushing) are represented by areas on the classroom floor. Forms of energy are indicated by hand signs or body movements; for example, these students indicate motion energy by pumping bent arms as in jogging. Energy transfers are indicated by people moving from one object area to another (e.g., from the area representing the person doing the pushing to the area representing the box). In using this representation to illustrate the energy involved when a person pushes a box with her hand, Ms. Allen's students show that motion energy transfers from the pusher's hand to the box, and, in one group's representation, from the box to the air. Ms. Allen asks whether the only energy available for transfer is the motion energy that the hand already has, or whether motion energy can be generated from other forms of energy in the person (such as what she calls "nutritional energy," associated with food consumed by the person pushing the box).

1. Ms. Allen: This brings up a good question. If I have motion energy in my hand, because my hand is moving, and I have the box that's moving, is the only energy that can transfer from my hand motion energy? Or, can energy that's in my hand as nutritional energy, can it change forms and become motion energy? What do you think?

2. Adam: Yeah!
3. Jill: That's what we did.

4. Ms. Allen: Ok.

5. Claire: So the heat and the motion in the hand were still in the hand.

6. Ms. Allen: Ok.

7. Grace: But we didn't have nutrition...turn into...

8. Ms. Allen: Ok, so could the heat from the hand change, could the, what do you think?

9. Grace: Could the heat change into motion?

10. Ms. Allen: Is that possible? Can energy do that? Can energy change from heat into motion energy?

11. Adam: No. No.

12. Student: Yes.

13. Jill: Wait, ohh...

14. Ms. Allen: Can you give me an example where you see heat change into motion? Yes.

15. Toby: Oh, rockets. So, heat, it heats up water, and then the water turns into steam, and then the steam touches a turbine, the turbine spins...

16. Dan: Whoa, whoa dude, that...

17. Toby: ...a magnet...

18. Ms. Allen: So there's a nice complicated one.

19. Adam: Popcorn! Pop.

20. Ms. Allen: We start out with heat energy and we end up with motion energy.

21. Grace: Popcorn.

22. Adam: Soup!

23. Ms. Allen: Popcorn, boiling water, okay?

24. Will: Soup, that's what Adam said!

25. Ms. Allen: Okay!

In response to Ms. Allen's initial question in line 1, students assert that their original representation showed nutritional energy transforming to motion energy (which could then transfer to the box). Claire says that therefore "the heat and motion in the hand" could remain in the hand, suggesting that the transformation of nutritional energy to motion energy provides a continual supply of motion energy to be transferred to the box. Ms. Allen inquires whether the "heat" (thermal energy [34]) in the hand could transform into motion energy as well, and students reflect briefly on whether that particular transformation process occurs in nature. Various students suggest examples of such processes: rockets, steampowered turbines, and popcorn.

Ms. Allen's initial inquiry is based on her observation and interpretation of the students' Energy Theater representation: She saw them transferring motion energy from the hand to the box, and inferred their model of energy supply. In particular, she asked, "....is the only energy that can transfer from my hand motion energy?," raising the possibility that their model might have a limited supply of energy available for transfer (the motion energy already in the hand). Ms. Allen's question reveals specific content knowledge, particularly regarding energy conservation and transfer: Ms. Allen uses the knowledge that there is a constant quantity of 
motion energy in the hand and that energy leaves the hand to go to the box. Our evidence of her content knowledge is in the questions she asks that highlight a particular feature of students' ideas. Her subsequent questions also present evidence of her content knowledge, in that she uses questions to direct student attention to content issues the students had not been discussing: she inquires whether the supply of motion energy in the hand may be renewed by transformation of nutrition energy to motion energy, and whether there might also be other transformations in the body that produce motion energy. In other words, her questions show her knowledge of allowable energy transfers and transformations. Ms. Allen's inquiries also suggest her knowledge of student ideas: she suspects students may not recognize the need for (or the source of) a continual supply of motion energy in the person, and may not recognize constraints on energy transfers and transformations. Overall, the conversation shows Ms. Allen using energy content knowledge (e.g., that there is a constant amount of motion energy in the hand even as energy transfers from the hand to the box) and knowledge of student ideas (e.g., that students may not recognize the continual resupply of energy to the hand) to accomplish a task of teaching (using students' expressed ideas to infer their model of energy supply). In other words, this conversation includes evidence of Ms. Allen's CKT-E.

\section{Ms. Allen infers students' sense of energy accumulation and spreading}

In a second episode from the same class period, Ms. Allen again uses students' expressed ideas to infer their model of energy. As the class continues to discuss the energy transfers and transformations that occur as a person pushes a box with her hand, Ms. Allen uses their Energy Theater representation to infer their sense of energy accumulation and spreading. In particular, she inquires about the end point of their Energy Theater, asking how it would have proceeded if they had an unlimited number of people to represent units of energy. Next, she asks how the two different groups' Energy Theater performances differ at the end.

1. Ms. Allen: If you had an unlimited number of people, how would you have continued your theater?

2. Adam: We would have kept...

3. (Students talking over each other.)

4. Wendy: We would have kept going, so everyone, so if someone transferred over, someone had to switch to heat.

5. Ms. Allen: Ok.

6. Adam: 'Cause that way it shows, like, constant...

7. Greg: That way it shows a constant speed.

8. Wendy:...speed

9. Ms. Allen: Beautiful. People, hold on, hold on, people on the floor stay on the floor. This way, people on the floor quiet. Abdul, because you were talking right now you get to start us off.
11. Students: Yes! (Clapping)

14. Ms. Allen: What is the first, what is the main thing that was different between your skit and theirs? It was at the very end.

15. Student: Different signs?

16. Student: Can I use a shout out?

17. Ms. Allen: They were different signs. Okay...

18. Abdul: Oohh yeahh they...

19. Ms. Allen: ...shh, I just wanna hear Abdul's words at the moment.

20. Abdul: ...their energy stayed in the box, where our energy went out to the room and the environment.

21. Ms. Allen: Their heat stayed in the box, the other troop, their heat went out into the environment. Here's my question: which one's right? Are both of them right?...

22. Madeline: Both of them...

23. Ms. Allen:...are they...

24. Madeline: Both of them could be.

25. Madeline: It's gonna put off heat but there's still gonna be heat in the box, so I guess, both are somewhat...

26. Dino: Both are right both are wrong.

27. Grace: I'm confused, because their friction and heat was the same thing. Are they the same or are they different?

28. Madeline: Heat is (inaudible) friction.

29. Ms. Allen: Ooh! That's a good question. Let's put that on pause for half a second and finish this question, okay?...

30. (Students talking.)

31. Ms. Allen: ...remember that question, Grace, we're coming back to it okay? Alright, so hold on. Let's run with this. If this Energy Theater were to go on forever, okay, eventually what would happen inside the box?

32. Ann: It would blow up!

33. Aaron: It would catch fire and go pchow.

34. Ms. Allen: It would catch fire. You would have so much heat inside the box if would just explode.

35. Beth: Okay so some of it eventually has to leave.

36. Student: Yeah, like what we did!

37. Ms. Allen: Some of it eventually has to leave.

38. Grace: But what we did, we had all of our heat exit, so wouldn't you just have one? One stays?

39. Ms. Allen: Okay. Say it again?

40. Grace: We had like, they had no heat leave but we had all of ours, but if there's heat in the environment and in the box wouldn't just one leave so it's like one and one?

41. Ms. Allen: Okay. What do you guys think? Couldn't it be heat in the environment and in the box?

42. Students: Yes.

43. Ms. Allen: Okay! I agree with that.

In response to Ms. Allen's question about the difference between the two Energy Theater performances, students 
initially state that the difference is in the hand signs used to indicate thermal energy (one group used a T sign whereas the other used a fanning motion). Ms. Allen then draws attention to Abdul's statement: "Their energy stayed in the box, where our energy went out to the room and the environment." Students appear unable to decide which of these correctly describes what actually happens to the energy (or if they are "both right," as Ms. Allen offers). Ms. Allen next asks what would happen to the box if one group's Energy Theater (in which thermal energy accumulates in the box) were to "go on forever." Students state that the box would suffer catastrophic consequences ("blow up," "catch fire") due to the accumulation of thermal energy, and conclude that since these consequences do not take place, some energy must leave the box. The conversation concludes with Ms. Allen's affirmation that there could be thermal energy in both the environment and the box.

As in the first episode, Ms. Allen's initial inquiry is based on her observation and interpretation of the students' Energy Theater representation. This time, she sees a difference in the end point of the two groups' Energy Theater representations, and infers a difference in the students' sense of energy concentration and spreading: some students show thermal energy accumulating in the box (and not transferring to the environment), whereas others show thermal energy transferring to the environment (and not accumulating in the box). Ms. Allen's attention to this issue suggests her content knowledge that in real, irreversible processes, energy spreads (within objects, to other objects, and through space, among other possibilities) - a statement of the second law of thermodynamics appropriate for secondary learners [35]. Our evidence of her content knowledge is in the questions she asks, which highlight a particular feature of students' ideas (their sense of energy concentration and spreading). Her interactions with her students further suggest her knowledge of student ideas: some of them seem to know that energy accumulates in the box, and others seem to know that energy transfers to the environment, but none of them display a sense that in the course of the scenario, energy spreads more equitably through the system (being distributed among the various objects in the system). In sum, Ms. Allen uses energy content knowledge (energy spreads) and knowledge of student ideas (energy transfers or accumulates) to accomplish a task of teaching (using students' expressed ideas to infer their energy model for this case).

\section{Mr. Brown infers students' sense of the dependence of potential energy on height}

In our final example of using students' expressed ideas to infer their model of energy, another secondary teacher, Mr. Brown, infers students' model of gravitational energy. In this conversation, students share their analysis of a scenario in which a $5 \mathrm{~kg}$ ball is lifted vertically to a

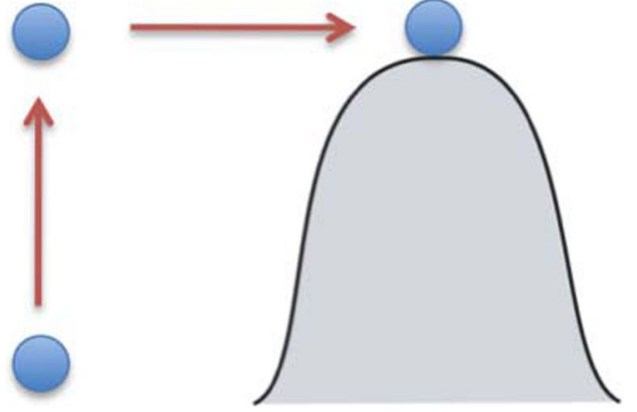

FIG. 4. Scenario from Mr. Brown's conversation with students.

height of $3 \mathrm{~m}$, then moved horizontally over one slope of a hill, so that eventually it touches the ground at the top of the hill. (The scenario is depicted in Fig. 4, but only a text description was provided to the students-no diagram. Energy Theater is not used in this class and is not part of the students' analysis.) Students are asked how much gravitational potential energy the ball has (1) when it is first lifted to a height of $3 \mathrm{~m}$, and (2) when it is set on the top of the hill; the correct answer is that the ball has $150 \mathrm{~J}$ of gravitational potential energy at both locations. However, one student, Peter, emphasizes the lessening "distance between the hill and the ball," and Mr. Brown infers that the students' model has the gravitational energy of the ball lessening in proportion to that distance.

1. Mr. Brown: So...what happened to the 150 joules that Lauren gave the bowling ball?

2. Peter: I guess we could say, let's say she walked up this hill or whatever.

3. Mr. Brown: Sure.

4. Peter: As she gets closer to, um, the same height as the ground up there...

5. Mr. Brown: Yup.

6. Peter: Then the total height changed from three meters to zero meters, and therefore it has zero potential.

7. Mr. Brown: I'm confused about total height, because total, it's usually like I add a couple of heights together. So...

8. Peter: So I guess the initial height then, at three meters, decreased to zero.

9. Mr. Brown: How?

10. Ruth: 'Cause you went up the hill.

11. Mr. Brown: The ball was already at that height, like, you had lifted it three meters up, and then you just moved it horizontally. (Gesturing this with his hand.)

12. Ruth: But the ball got closer to the hill.

13. Mr. Brown: Okay.

14. Ruth: So the height, or the distance between the hill and the ball got less. And then it was zero.

15. Mr. Brown: Okay. Got it, got it. Okay. Um, so... when the ball's halfway horizontally, is the gravitational energy half of what it was?

16. Nan: (Nods yes.) The height is. 
17. Mr. Brown: So then, if I calculate U-G [gravitational energy], then it'd be getting smaller and smaller as I move toward the top of the hill.

18. Students: (Nod yes.)

In line 11, Mr. Brown says the ball was "already" at the given height, and then "you just moved it horizontally," suggesting his own content knowledge that horizontal movement does not change an object's height (or gravitational energy). Our evidence of his content knowledge is in his addition to Peter's statement: Peter says the height decreases to zero, and Mr. Brown says the ball started at a height of $3 \mathrm{~m}$ and then moved horizontally. The students, however, assert that as the ball gets closer to the hill, its height is decreasing from the surface. From their statements, Mr. Brown gains knowledge of his students' ideas: They seem to think that the height of an object is the distance between the object and the surface beneath it (perhaps especially if that surface is the surface of the earth). Mr. Brown asks whether the gravitational energy of that object is proportional to this "height," and his students state that it is. Thus, Mr. Brown uses students' statements to infer their sense of the dependence of potential energy on height - an example of using their expressed ideas to infer their model of energy, and an example of CKT-E in action.

\section{B. Revoicing students' ideas}

Another interactional task of teaching energy is for the instructor to revoice the energy ideas that students express. Revoicing shows knowledge of student ideas: it shows understanding of the ideas that are being revioiced, and also often indicates knowledge of common student ideas from the literature (that are related to the revoiced idea). This instructor revoicing has multiple potential purposes, e.g., to check instructor understanding of an idea, to support students in engaging with each other's ideas, and to show that the idea has value for the classroom discourse [36]. In the examples that follow, teachers revoice student ideas about energy to (a) elevate a particular idea for class discussion and (b) indicate and/or check their understanding.

\section{Ms. Allen revoices student ideas about friction and heat}

In the following episode, Ms. Allen revoices a question posed by a student in an earlier episode (Sec. VA 2) about whether friction and heat are the same thing. The student's statement was specifically, "I'm confused, because their friction and heat was the same thing. Are they the same or are they different?" (line 27). At that time, Ms. Allen had said, "Ooh! That's a good question. Let's put that on pause for half a second" (line 29). Shortly thereafter, Ms. Allen revoices the student's question, elevating it for the class' consideration.

1. Ms. Allen: Alright, let's come back to Grace's question. It was, are friction and heat the same thing?

2. Beth: No.
3. Ms. Allen: What do you think?

4. Grace: Well 'cuz their sign...

5. Adam: Heat is energy, friction is friction. Got it!

6. Student:...for friction...

7. Ms. Allen: One at a time, guys.

8. Grace:...their sign represented friction and heat they said, so...

9. Adam: This was heat, I don't know why they

10. Grace:.... if friction and heat are the same thing in theirs then I'm confused.

11. Ms. Allen: Okay.

12. Toby: Friction creates heat though.

13. Ms. Allen: Friction creates heat.

14. Adam: Heat is energy, friction is a force

15. Ms. Allen: Heat is energy, friction is a force. That is a very true statement.

Ms. Allen's choosing to highlight this student's question ("Are friction and heat the same thing?") suggests her content knowledge that friction and heat are distinct quantities in physics, as well as her knowledge that students may conflate the two (which she may have learned during the preceding episode). In this new exchange, students respond to the question about friction and heat: Adam asserts that "heat is energy" (consistent with the commonlanguage use of the term "heat" for thermal energy [34]); Toby chimes in that "friction creates heat"; Adam elaborates his earlier statement with "Heat is energy, friction is a force." Our evidence of her content knowledge is in Ms. Allen prioritizing a certain part of what each student says: she revoices the statements that "friction creates heat" and "Heat is energy, friction is a force," particularly validating the second one with "That is a very true statement." In this episode, Ms. Allen uses energy content knowledge (friction and heat are distinct quantities) and knowledge of student ideas (students conflate friction and heat) to accomplish a task of teaching (highlighting a student's question through revoicing). In other words, she demonstrates her content knowledge for teaching energy.

\section{Mr. Brown revoices student ideas about gravitational energy}

In this episode, Mr. Brown continues his discussion with students about the dependence of gravitational energy on height, including the meaning of "height." Mr. Brown has already determined that his students think the height of an object is its vertical distance from the surface below the object, such that if an object is moved horizontally over a slanted surface (such as a hill), the object's height would be considered to be changing, and its gravitational energy along with it. Mr. Brown, meanwhile, understands height (and gravitational energy) to remain constant through horizontal displacement. Mr. Brown revoices the students' idea that the energy imparted to a lifted object seems to "go away" when you move it sideways: 
1. Mr. Brown: I guess I'm still, I'm still stuck on the idea that you lifted it all the way to three meters above your feet, and all you do is you move it sideways and all that energy you put in there goes away. We're trying to figure out where it goes right? So, if I put the ball at two meters on the hill and let go of it, what would it do?

2. Peter: Roll down.

3. Mr. Brown: And if I drop the ball from two meters it would fall down into, it would just fall straight instead of rolling diagonally. So is the problem that it's on a flat part of the hill? Like if my hill kept going up and up and up at an angle, and I put it three meters up the hill would it just roll for three meters?

4. Ruth: But the height is still zero. Like right here (pointing to worksheet) the height is zero.

5. Peter: Yeah.

6. Mr. Brown: Ah.

7. Ruth: So the gravitational energy is still zero. So the reason why it's moving is because of the hill.

8. Peter: And the potential energy.

9. Ruth: Not because of the energy I gave it.

10. Peter: Because you're...

11. Mr. Brown: How did it get to the top of the hill?

12. Connie: Because you gave it energy.

13. Mr. Brown: Whoever was lifting it right? You did, somebody did work to get it there. But as soon as you put it down on the hill, all the energy goes away.

14. Students: Yeah.

Mr. Brown's revoicing of the students' idea in line 1 suggests his content knowledge that when you lift a ball, you give it energy: he says that after "you lifted the ball all the way to three meters above your feet," "all that energy" seems to go away. His statement also shows his content knowledge that energy is conserved-he is seeking an account for where the energy comes from and where it goes. Our evidence of Mr. Brown's content knowledge is in his additions to student statements: the suggestion that lifting the ball is associated with energy that should not "just go away" is his own contribution. There is also evidence that Mr. Brown gains knowledge of student ideas: in line 13, he revoices his students' explanation for why the energy of the ball (on the hill) is zero as, "You did work to get it there, but as soon as you put it down on the hill, all the energy goes away," and the students affirm his restatement of their idea. ${ }^{4}$ In this episode, Mr. Brown uses his energy content knowledge (that when you lift a ball you give it energy, and that energy is conserved) and knowledge of student ideas (students think that an object touching the ground has no gravitational energy, even on a hill) to selectively revoice students' ideas, indicating and/or checking that he understands their reasoning.

\footnotetext{
${ }^{4}$ Peter attributes the movement to "potential energy," which Mr. Brown does not revoice at this time; later, he suggests that the term does not yet have a consensus meaning in this class.
}

\section{Choosing an instructional activity to address students' misunderstandings}

One of an instructor's tasks is to choose instructional activities or explanations that address students' misunderstandings. Such student misunderstandings may be known in advance (e.g., from literature on common student ideas) or detected in the moment (e.g., when the instructor interprets student statements); in either case, knowing students' misunderstandings is one form of knowledge of student ideas. In what follows, teachers select instructional activities or analogies to help students refine their understanding of energy. In so doing, they convey both their energy content knowledge and their knowledge of student ideas about energy (i.e., their CKT-E).

\section{Mr. Brown chooses a question to elicit the idea that an object on a hill has no gravitational energy}

In episodes we have already described, Mr. Brown has extensive discussions with students about gravitational energy after presenting them with the scenario in Fig. 4 where a ball is raised three meters and then displaced horizontally and set on a hill. Mr. Brown asks his students to compute the gravitational potential energy of the ball (a) after it has been raised and (b) after it has been set on the hill. In Sec. VA 3, Mr. Brown infers students' sense of the dependence of potential energy on height. In Sec. V B 2, Mr. Brown revoices students' idea that an object touching the ground has no gravitational energy (even on a hill). Both of these tasks of teaching take place in the context of a question that Mr. Brown selected for the purpose of eliciting students' potential misunderstandings about gravitational energy - in particular, the misunderstanding that the gravitational energy of an object is determined by its distance from the surface below it (especially if that surface is the ground), rather than by its height above an established point of reference. Our evidence of Mr. Brown's content knowledge is in his selection of this question: he knows that gravitational energy is unchanged under horizontal translation. He also shows his knowledge of student ideas: he knows that some students think that potential energy is determined by an object's distance above the ground. In other words, his choice of instructional activity exhibits his CKT-E.

\section{Ms. Clark plans an activity to elicit the idea that the gravitational energy of an object depends on what is supporting it}

Another secondary teacher, Ms. Clark, selects a different instructional activity to address another incorrect student idea about gravitational energy: the idea that the gravitational energy of an object depends on what is supporting the object. For this activity, Ms. Clark arranges three identical balls—a, b, and c (Fig. 5)—at the same height but with different supports: one floating in water (a), one 


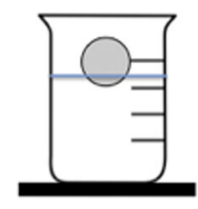

(a)

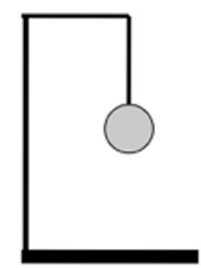

(b)

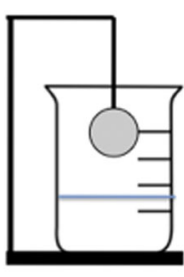

(c)
FIG. 5. Depiction of three balls in Ms. Clark's instructional activity.

hanging from a string (b), and one hanging from a string above a water surface (c). She asks her students to rank the gravitational energy of the three objects (a, b, and c). In explaining the answer she expects, Ms. Clark also tells her students her motivation for posing the question:

Finally, number two. What was the ranking for number two? $a, b, c$ are all equal, simply because they are the same height from the table... I did wanna throw you off, I was hoping, not, I wasn't trying to throw you off. I was hoping that it was a little bit confusing in that the water right here is full, this one's full and this one's only like halfway full of water, so it seems like there has to be something like, there's more stuff here, pushing up the ball. But the idea is that it has nothing to do with what's supporting it, it only has to do with their height and their mass. Since they all have the same mass, we're on the same Earth so the g stays the same, the only thing that's different is their height. Is that clear?

Our evidence of Ms. Clark's content knowledge is in her selection of this instructional activity, which is intended to demonstrate that the gravitational energy of an object depends only on its height, its mass, and the gravitational constant $g$. She chose this activity based on her knowledge of student ideas: her intent was to elicit and address the incorrect idea that an object's gravitational energy depends on what's supporting it. (Mr. Brown's students may be using a related idea in Sec. VA 3 and V B 2.) Ms. Clark's choice of activity shows not only her CKT-E, but also her pedagogical knowledge more broadly: she shares that she was hoping for this to be "a little bit confusing," consistent with an instructional theory informed by Piagetian accommodation [37] or "elicit, confront, resolve" [38,39].

\section{Ms. Clark plans an activity to illustrate that moving objects can have gravitational energy}

In another interaction during the same lesson as above, Ms. Clark illustrates the idea that moving objects can have gravitational energy as well as motion energy. This is another example of Ms. Clark choosing an instructional activity to address students' misunderstandings; in this case, she describes herself explicitly as "addressing a big misconception" (presumably, that an object can have either motion energy or potential energy but not both). Her knowledge of student ideas is supported by literature documenting a historical concept of potential energy as latent or hidden energy, signifying the object's "potential" to move [40]. She addresses this misunderstanding with a computer simulation called Energy Skate Park [41], which shows multiple forms of energy associated with a person on a skateboard as he rides up and down a curved track.

1. Ms. Clark: Ok. So let's address this, let's address this big misconception. There's a common misconception-there's a common idea that if something is moving, that it can't have any more gravitational potential energy. Do you guys see why that's not necessarily true now? Why is that not true, Lindsey? Can something be moving and have gravitational potential energy?

2. Lindsey: Well yeah if it's off the ground.

3. Ms. Clark: So this is like the bar graph idea, do you remember the skate park skater? The skater when he was all the way up on the side of the half pipe he had full potential energy, as he was going down the half pipe, once he was like midway he had half of his gravitational potential energy had been turned into kinetic, but he still had half as much, cause he was still, he still had area to drop, he still had height to cover (hand gesturing height). So when the ball was right here, even though it did have some velocity it was still above the ground, so it still had gravitational potential energy. Did the ball ever have zero gravitational potential energy at 90, 60, or 30? (Pauses) I should see, like, lots of heads nodding or not right now. Did the ball ever have zero gravitational potential energy when it was falling?

4. Student: No.

5. Ms. Clark: At 90, 60, or 30. No, it never did, because at 90,60 , and 30 it's still above (pounding on table) the table.

Again, our evidence of Ms. Clark's content knowledge is in her selection of this instructional activity, which seems designed to demonstrate that the gravitational energy of an object depends on its height and is independent of its motion energy. She chose this activity based on her knowledge that students may think gravitational energy, being a form of potential energy, is an alternative to motion energy - the kind of energy that an object has when it isn't moving. In this episode we see Ms. Clark's energy content knowledge and her knowledge of student ideas being used in the service of a task of teaching: choosing an instructional activity to address students' misunderstandings. Thus, this episode is another example of Ms. Clark's CKT-E.

\section{Evaluating student ideas}

The final task of teaching that we will illustrate is that of evaluating student ideas. Evaluation requires knowledge of student ideas: teachers engaging in this task are interpreting 
student statements in real time to learn what students know, and then relating that information to canonical knowledge to evaluate correctness. In what follows, teachers react to students' energy statements in various evaluative ways. As they do so, they show their energy content knowledge and their knowledge of student ideas about energy (i.e., their CKT-E).

\section{Ms. Clark evaluates student suggestion that combustion is a form of energy}

In the following brief interaction, Ms. Clark is in the middle of making a list of forms of energy suggested by students. Ella suggests that "combustion" be added to the list, and Ms. Clark explains why this would be inappropriate.

1. Ella: Combustion?

2. Ms. Clark: Combustion. What do you think that means?

3. Henry: Explosions!

4. Ms. Clark: Combustion means explosions? So combustion is whenever oxygen reacts with something, so that does produce energy, but it's not necessarily a form of energy.

In this episode, Ms. Clark shows her content knowledge that combustion is a chemical reaction with oxygen that "produces energy" (i.e., transforms chemical energy into other forms, such as motion energy, thermal energy, and light). Our evidence of her content knowledge is in her addition to the student's statement: after repeating what the student said, she states her own definition of combustion. She also shows her knowledge that students think (or at least Ella thinks) of combustion as a form of energy; she may even be aware that students sometimes confuse forms of energy with means of energy production $[30,42,43]$. Thus, her evaluation of this student's response exhibits her CKT-E.

\section{Ms. Clark evaluates student proposal that gravitational energy is independent of weight}

In another brief interaction, Ms. Clark responds to suggestions from students as to what variables do and do not influence an object's gravitational energy. Brian suggests that "weight and elasticity" do not matter for gravitational energy, and Ms. Clark explains why this is not correct.

1. Brian: Weight and elasticity.

2. Ms. Clark: Weight, unfortunately, does matter, because weight is this combo right here (pointing to something on the white board). Weight is the combination of mass times the gravitational field strength. So technically you could also say that E-P-G [Energy-Potential-Gravitational] depends on weight times height. Do you see why? Because weight is basically just mass and acceleration due to gravity, or $g$.

In this episode, Ms. Clark responds to Brian's statement using specific content knowledge: that gravitational energy is the product of an object's weight and height, and therefore depends on the object's weight. Our evidence of her content knowledge is again in her addition to the student's statement: Brian asserted that weight does not matter, and Ms. Clark added an explanation of how weight relates to mass and gravitational field strength (which appear in the equation for gravitational potential energy). In responding to Brian she indicates knowledge that some students do not think gravitational energy depends on weight, but that students do know (or can easily recognize) the dependence: one route she knows will be accessible to them is through their knowledge that weight is the product of mass and the gravitational constant $(\mathrm{mg})$, while gravitational energy is the product of mass, the gravitational constant, and height $(m g h)$. Her brief evaluation of Brian's suggestion indicates her CKT-E.

\section{Ms. Allen ascribes value to student question about the difference between heat and friction}

In the episode described in Sec. VA 2, in which Ms. Allen and her students discuss the energy transfers and transformations that occur when a person pushes a box with her hand, Ms. Allen engages in a particular form of evaluation: She positively evaluates a question that a student poses about friction and heat.

1. Grace: I'm confused, because their friction and heat was the same thing. Are they the same or are they different?

2. Madeline: Heat is (inaudible) friction.

3. Ms. Allen: Ooh! That's a good question. Let's put that on pause for half a second and finish this question, okay?...

Though we can easily imagine teachers saying "that's a good question" as an encouraging placeholder, without necessarily meaning to evaluate the quality of the question, Ms. Allen affirms that she finds Grace's specific question worthwhile by returning to it later (Sec. V B 1). Her positive evaluation of this question (in the context of the full episode) indicates her content knowledge that friction and heat are distinct quantities (evidenced in her prioritizing a certain part of what students expressed), as well as her knowledge that students conflate friction and heat. In other words, this evaluative interaction demonstrates Ms. Allen's CKT-E.

\section{Mr. Brown affirms student calculation of gravitational energy}

During Mr. Brown's interaction with students about the dependence of gravitational energy on height (Secs. VA 3 and V B 2), Mr. Brown rapidly evaluates Peter's calculation of gravitational energy:

1. Mr. Brown: Um, and then somehow, I don't know how anybody would be able to do this or how Lauren's able to do this, but she lifts the ball all the way up to this height, so now it's $3 \mathrm{~m}$ above the 
ground. How much gravitational energy does it have now?

2. Peter: One hundred and fifty.

3. Mr. Brown: You guys are good!

In order to offer this positive evaluation, Mr. Brown uses content knowledge of how to calculate gravitational energy, probably as the product of mass, the gravitational constant, and height $(m g h)$. In other words, our evidence of his content knowledge is his positive evaluation of a correct student idea. The interaction also suggests that he knows his students have content knowledge of how to calculate gravitational energy, given that they obtain the correct answer. Mr. Brown's content knowledge and his knowledge of student ideas serve him directly in evaluating student ideas.

\section{DISCUSSION}

Our goal in analyzing these episodes has been to illustrate a methodology for identifying CKT-E-in-use in interactional tasks of teaching. In particular, we gave several examples of teachers engaging in interactional tasks of teaching, each one characterized in terms of how the teachers were acting on students' ideas about energy. We identified teachers' content knowledge on the basis of their selections from and additions to student statements. We identified their KSI in responses that were plausibly informed by an understanding of their students' actions or statements, or by an understanding of literature about student ideas about energy. Our hope is that this methodology can serve other researchers in answering questions about what teachers need to know to teach a particular topic, and in pursuing the broader question of whether teacher knowledge matters for instructional practice or student learning. As suggested by Alonzo and Kim [20], most measures of teacher knowledge focus on declarative PCK, and our field needs measures of dynamic PCK-or PCK that serves teachers in the moment, as they interact with students. Our work makes progress in this direction.

Our work also has implications for the design of teacher professional development aimed at enhancing teacher content knowledge about energy. It is noteworthy to us that in the episodes we analyzed, different teachers drew on the same knowledge for very different tasks of teaching.
For example, both Mr. Brown and Ms. Clark draw on their content knowledge that an object's gravitational energy depends on its height. However, Mr. Brown draws on this knowledge to infer his students' model for what happens to a ball as it moves horizontally toward the top of a hill, whereas Ms. Clark uses this knowledge to plan an activity that anticipates and addresses students' incorrect ideas. These differences highlight the importance of not only developing teacher knowledge but also considering how this knowledge will be used, in practice. Relatedly, our original expectation in analyzing episodes from teacher classrooms was that we would see themes in teachers' knowledge that might tell us something about what teachers need to know to interact with students' ideas about energy. However, no clear themes emerged; it was not the case that most interactions required knowledge of, for example, energy indicators or of how to delineate a system of objects. Together, these two observations suggest that teacher education both (a) should take into consideration how teachers are expected to use their knowledge in practice (e.g., consider the tasks of teaching that teachers are expected to engage in) and (b) need not focus on teacher learning of a fixed body of knowledge (i.e., our evidence does not point to a single, coherent set of ideas that teachers use in practice). Given recent STEM education reforms $[6,7]$ and classroom research that emphasizes the importance of attending to and building on students' intuitive ideas $([8-12,14,15])$, we suggest that teacher professional development supports teachers in recognizing and responding to the energy ideas embedded in students' talk and action, in concert with or in addition to supporting teachers in developing their own energy knowledge and pedagogical content knowledge.

\section{ACKNOWLEDGMENTS}

This material is based upon work supported by National Science Foundation Grant No. 122732. We gratefully acknowledge the thoughtful feedback offered by three anonymous reviewers, by members of the PER@SPU research team-including Lezlie S. DeWater, Sarah B. McKagan, Lane Seeley, and Stamatis Vokos—and by Drew Gitomer at Rutgers University.
[1] L. S. Shulman, Those who understand: Knowledge growth in teaching, Educ. Res. 15, 4 (1986).

[2] L.S. Shulman, Knowledge and teaching: foundations of the new reform, Harv. Educ. Rev. 57, 1 (1987).

[3] D. L. Ball and H. Bass, Toward a practice-based theory of mathematical knowledge for teaching, in Proceedings of the 2002 Annual Meeting of the Canadian Mathematics
Education Study Group, edited by B. Davis and E. Simmt (CMESG/GCEDM, Edmonton, AB, 2003), p. 3.

[4] D. L. Ball, M. H. Thames, and G. Phelps, Content knowledge for teaching: what makes it special?, J. Teach. Educ. 59, 389 (2008).

[5] E. Mtethwa-Kunene, G. O. Onwu, and R. de Villiers, Exploring biology teachers' pedagogical content knowl- 
edge in the teaching of genetics in Swaziland science classrooms, Int. J. Sci. Educ. 37, 1140 (2015).

[6] NGSS Lead States, Next Generation Science Standards: For States, by States (National Academies Press, Washington, DC, 2013).

[7] National Governors Association Center for Best Practices and Council of Chief State School Officers, Common Core State Standards for Mathematics (Washington, DC, 2010).

[8] J. E. Coffey, D. Hammer, D. M. Levin, and T. Grant, The missing disciplinary substance of formative assessment, J. Res. Sci. Teach. 48, 1109 (2011).

[9] D. Hammer, Discovery learning and discovery teaching. Cognition and instruction, Cognit. Instr. 15, 485 (1997).

[10] D. Hammer, F. Goldberg, and S. Fargason, Responsive teaching and the beginnings of energy in a third grade classroom, Rev. Sci. Math. ICT Educ. 6, 51 (2012).

[11] D. Hammer and E. van Zee, Seeing the Science in Children's Thinking: Case Studies of Student Inquiry in Physical Science (Heinemann, Portsmouth, NH, 2006).

[12] D. Levin, D. Hammer, A. Elby, and J. Coffey, Becoming a Responsive Science Teacher: Focusing on Student Thinking in Secondary Science (National Science Teachers Association Press, Arlington, VA, 2012).

[13] A. D. Robertson, L. J. Atkins, D. M. Levin, and J. Richards, What is responsive teaching?, in Responsive Teaching in Science and Mathematics, edited by A. D. Robertson, R. E. Scherr, and D. Hammer (Routledge, New York, NY, 2016), p. 1.

[14] A. D. Robertson, R. E. Scherr, and D. Hammer, Responsive Teaching in Science and Mathematics (Routledge, New York, NY, 2016).

[15] D. L. Ball, With an eye on the mathematical horizon: Dilemmas of teaching elementary school mathematics, Elem. School J. 93, 373 (1993).

[16] Bibliography-Students' and Teachers' Conceptions and Science Education, http://www.ipn.uni-kiel.de/aktuell/stcse/.

[17] R. Driver, E. Guesne, and A. Tiberghein, Children's Ideas in Science (Open University Press, Philadelphia, PA, 1985).

[18] L. C. McDermott and E. F. Redish, Resource letter: PER-1: Physics education research, Am. J. Phys. 67, 755 (1999).

[19] R. K. Sawyer, Creative teaching: Collaborative discussion as disciplined improvisation, Educ. Res. 33, 12 (2004).

[20] A. C. Alonzo and J. Kim, Declarative and dynamic pedagogical content knowledge as elicited through two video-based interview methods, J. Res. Sci. Teach. 53, 1259 (2016).

[21] P. L. Grossman, The Making of a Teacher: Teacher Knowledge and Teacher Education (Teachers College Press, Columbia University, New York, 1990).

[22] J. Gess-Newsome, Secondary teachers' knowledge and beliefs about subject matter and their impact on instruction, in Examining Pedagogical Content Knowledge: The Construct, and its Implications for Science Education, edited by J. Gess-Newsome and N. G. Lederman (Kluwer Academic Publishers, Dordrecht, Netherlands, 1999), p. 51.

[23] S. K. Abell, Research on science teacher knowledge, in Research on Science Teacher Education, edited by S. K. Abell and N. G. Lederman (Routledge, New York, NY, 2007), p. 1105.
[24] J. H. van Driel, A. Berry, and J. Meirink, Research on science teacher knowledge, in Handbook of Research on Science Education, edited by N. G. Lederman and S. K. Abell (Routledge, New York, NY, 2014), p. 848.

[25] S. Magnusson, J. Krajcik, and H. Borko, Nature, sources, and development of pedagogical content knowledge for science teaching, in Examining Pedagogical Content Knowledge: The Construct and its Implications for Science Education, edited by J. Gess-Newsome and N. G. Lederman (Kluwer Academic Publishers, Dordrecht, Netherlands, 1999), p. 95.

[26] E. Etkina, Pedagogical content knowledge and preparation of high school physics teachers, Phys. Rev. ST Phys. Educ. Res. 6, 020110 (2010).

[27] E. Etkina, L. Seeley, and S. Vokos, Pedagogically relevant content knowledge as a necessary of sufficient condition for attending productively to student ideas about energy, Phys. Rev. Phys. Educ. Res. (to be published).

[28] B. Jordan and A. Henderson, Interaction analysis: Foundations and practice, J. Learn. Sci. 4, 39 (1995).

[29] D. Hammer and A. Elby, Tapping epistemological resources for learning physics, J. Learn. Sci. 12, 53 (2003).

[30] R. E. Scherr, H. G. Close, S. B. McKagan, and S. Vokos, Representing energy. I. Representing a substance ontology for energy, Phys. Rev. ST Phys. Educ. Res. 8, 020114 (2012).

[31] A. R. Daane, L. Wells, and R. E. Scherr, Energy theater, Phys. Teach. 52, 291 (2014).

[32] R. E. Scherr, H. G. Close, A. R. Daane, L. S. DeWater, B. W. Harrer, A. D. Robertson, L. Seeley, and S. Vokos, Energy tracking diagrams, Phys. Teach. 54, 96 (2016).

[33] R. E. Scherr, H. G. Close, S. B. McKagan, and S. Vokos, Representing energy. II. Energy tracking representations, Phys. Rev. ST Phys. Educ. Res. 8, 020115 (2012).

[34] P. A. Kraus and S. Vokos, The Role of Language in the Teaching of Energy: The Case of 'Heat Energy', (Washington State Teachers' Association Journal, 2011).

[35] A. R. Daane, S. Vokos, and R. E. Scherr, Goals for teacher learning about energy degradation and usefulness, Phys. Rev. ST Phys. Educ. Res. 10, 020111 (2014).

[36] M. C. O'Connor and S. Michaels, Aligning academic task and participation status through revoicing: Analysis of a classroom discourse strategy, Anthrop. Educ. Q. 24, 318 (1993).

[37] G. J. Posner, K. A. Strike, P. W. Hewson, and W. A. Gertzog, Accommodation of a scientific conception: Toward a theory of conceptual change, Sci. Educ. 66, 211 (1982).

[38] L. C. McDermott, Oersted Medal Lecture 2001: "Physics Education Research-The Key to Student Learning", Am. J. Phys. 69, 1127 (2001).

[39] L. C. McDermott, Millikan Lecture 1990: What we teach and what is learned-Closing the gap, Am. J. Phys. 59, 301 (1991).

[40] E. Hecht, An Historico-Critical Account of Potential Energy: Is PE Really Real?, Phys. Teach. 41, 486 (2003).

[41] See https://phet.colorado.edu/en/simulation/energy-skatepark.

[42] D. M. Watts, Some alternative views of energy, Phys. Educ. 18, 213 (1983).

[43] R. Trumper, Children's energy concepts: a cross-age study, Int. J. Sci. Educ. 15, 139 (1993). 